\title{
Induction of Vertebrate Regeneration by a Transient Sodium Current
}

\author{
Ai-Sun Tseng, ${ }^{1,2,3,4}$ Wendy S. Beane, ${ }^{1,2}$ Joan M. Lemire, ${ }^{1,2}$ Alessio Masi, ${ }^{1,2}$ and Michael Levin ${ }^{1,2,3,4}$ \\ ${ }^{1}$ Department of Biology and ${ }^{2}$ Center for Regenerative and Developmental Biology, Tufts University, Medford, Massachusetts 02155, and ${ }^{3}$ Forsyth Institute \\ and ${ }^{4}$ Harvard School of Dental Medicine, Boston, Massachusetts 02155
}

Amphibians such as frogs can restore lost organs during development, including the lens and tail. To design biomedical therapies for organ repair, it is necessary to develop a detailed understanding of natural regeneration. Recently, ion transport has been implicated as a functional regulator of regeneration. Whereas voltage-gated sodium channels play a well known and important role in propagating action potentials in excitable cells, we have identified a novel role in regeneration for the ion transport function mediated by the voltage-gated sodium channel, $\mathrm{Na}_{\mathrm{V}}$ 1.2. A local, early increase in intracellular sodium is required for initiating regeneration following Xenopus laevis tail amputation, and molecular and pharmacological inhibition of sodium transport causes regenerative failure. $\mathrm{Na}_{\mathrm{V}} 1.2$ is absent under nonregenerative conditions, but misexpression of human $\mathrm{Na}_{\mathrm{V}} 1.5$ can rescue regeneration during these states. Remarkably, pharmacological induction of a transient sodium current is capable of restoring regeneration even after the formation of a nonregenerative wound epithelium, confirming that it is the regulation of sodium transport that is critical for regeneration. Our studies reveal a previously undetected competency window in which cells retain their intrinsic regenerative program, identify a novel endogenous role for $\mathrm{Na}_{\mathrm{V}}$ in regeneration, and show that modulation of sodium transport represents an exciting new approach to organ repair.

\section{Introduction}

Humans have limited ability to repair injured or damaged organs. Interestingly, most mammalian organs contain resident progenitor cells (Zupanc, 2006), but it is not known why these cells are not mobilized for repair, suggesting that there may be an absence of instructive signals. Recently, it has become clear that biophysical signals such as ion currents and patterned voltage gradients (Reid et al., 2005; Adams et al., 2007) are key components for the induction of regeneration and patterning of new tissue in structures such as amphibian limbs and mammalian corneas (Zhao et al., 2006; Adams et al., 2007). To identify the molecular basis for regenerative currents in regeneration, we used Xenopus laevis - a powerful model that fully restores its larval appendages upon injury, uses pathways conserved to mammalian regeneration, and regenerates, as do mammals, through

\footnotetext{
Received June 26, 2010; revised Aug. 5, 2010; accepted Aug. 11, 2010.

This work was supported by the National Institutes of Health (Grant R01-GM078484 to M.L. and Grant F32-GM083547 to W.S.B.) and National Highway Traffic Safety Administration (Grant DTNH22-06-G-00001), Department of Defense (Grant W81XWH-10-2-0058), and Defense Advanced Research Projects Agency (Grant W911NF-07-1-0572) grants to M.L. We thank D. Adams for assistance with dye imaging and confocal microscopy, P. Koustubhan and A. Currier for their assistance with Xenopus husbandry, D. Qiu and J. Boltax for technical assistance and histology, and F. Miskevich for advice about generating RNAi targeting constructs. Clones for $\mathrm{XNa}_{\mathrm{v}} 1.2$ and $\mathrm{XNa}_{\mathrm{v}} 1.5$ were gifts from M. Kukuljan. Clone for $\mathrm{hNa} \mathrm{a}_{\mathrm{v}} 1.5$ was a gift from M. Djamgoz. The cloning vector for RNAi was a gift from $F$. Miskevich. We are grateful for the advice and support of P. Smith at the BioCurrents Resource Center

Correspondence should be addressed to Michael Levin, Center for Regenerative and Developmental Biology, Tufts University, Suite 4600, 200 Boston Avenue, Medford, MA 02155. E-mail: michael.levin@tufts.edu.

A. Masi's present address: Dipartimento di Farmacologia, Università degli Studi di Firenze, 50139 Firenze, Italy.

A.-S. Tseng, W. S. Beane, J. M. Lemire, and M. Levin's present address: Center for Regenerative and Developmental Biology, Tufts University, 200 Boston Avenue, Medford, MA 02155.

DOI:10.1523/JNEUROSCI.3315-10.2010

Copyright $\odot 2010$ the authors $\quad$ 0270-6474/10/3013192-09\$15.00/0
}

tissue renewal and not transdifferentiation (Gargioli and Slack, 2004; Slack et al., 2004; Chen et al., 2006).

The Xenopus larval tail is a complex organ containing multiple cell types: muscle, peripheral nerves, spinal cord, notochord, skin, and vasculature. After tail amputation, wound healing occurs within $6-8 \mathrm{~h}$ postamputation (hpa). By $24 \mathrm{hpa}$, an initial swelling containing progenitor cells, called the regeneration bud, is formed at the injury site. Subsequently, tissue outgrowth and patterning begin as the tail is rebuilt over $\sim 7 \mathrm{~d}$ (Beck et al., 2009).

Several molecular components regulating tail regeneration have been identified. TGF- $\beta$ signaling is required for proper wound healing and is detected at the wound as early as $15 \mathrm{~min}$ after amputation (Ho and Whitman, 2008). The proton $\left(\mathrm{H}^{+}\right)$ pump, V-ATPase, is active by $6 \mathrm{~h}$ postamputation, and its modulation of the transmembrane potential in regeneration bud cells is required during the first $24 \mathrm{hpa}$ (Adams et al., 2007). Apoptosis in the regeneration bud during the first $24 \mathrm{hpa}$ is also required for regeneration as in other systems (Tseng et al., 2007; Chera et al., 2009; Li et al., 2010). Components of signaling pathways such as BMP, Notch, Wnt, and FGF are expressed later and are involved in driving regenerative outgrowth and patterning (Beck et al., 2006; Mochii et al., 2007), recapitulating their well characterized roles during axial development. Several of these pathways have been targeted to induce regeneration of spinal cord and other tissues in nonregenerative states. To date, all of these functional interventions were applied before the actual injury. However, in order for significant advances in regenerative biomedicine to occur, it is necessary to identify new pathways that can be targeted by therapies to induce appendage regeneration after injury and nonpermissive wound healing. 
Here we identify a new mechanism controlling vertebrate regeneration by modulating in vivo sodium $\left(\mathrm{Na}^{+}\right)$transport, endogenously mediated by the voltage-gated sodium channel, $\mathrm{Na}_{\mathrm{V}}$ 1.2. Crucially, direct modulation of sodium transport is sufficient to induce vertebrate regeneration even after a nonregenerative wound epithelium has formed. Our data reveal a novel bioelectrical regulator of regeneration, and suggest a new therapeutic approach independent of transgenesis that can promote the regeneration of a complex appendage.

\section{Materials and Methods}

Tail regeneration assay. Xenopus laevis larvae were cultured via approved protocols (Institutional Animal Care and Use Committee, \#M2008-08). Tails at stages (st.) 40-41 (regenerative) or 45-47 (refractory period) (Nieuwkoop and Faber, 1967) were amputated at the midpoint between the anus and the tip. Tadpoles were cultured in $0.1 \times$ MMR, with or without reagent, at $22^{\circ} \mathrm{C}$ for $7 \mathrm{~d}$ and scored for tail regeneration. Unless indicated, $250 \mu \mathrm{M}$ MS222 (Sigma) was used for assays. To quantify and compare regeneration in groups of tadpoles treated with different reagents, we determined a composite regeneration index (RI), ranging from 0 (no regeneration) to 300 (complete regeneration) as described previously (Adams et al., 2007). This index, and the specific definitions of regeneration phenotype categories (full, good, weak, none) are given in supplemental Figure S1 (available at www.jneurosci.org as supplemental material). For example, a group of tails in which $>80 \%$ were fully regenerated would have an RI ranging from 240 to 300; if full regeneration occurred in $<10 \%$ of the animals within the group, the RI would range from 0 to 30 .

RNA interference and embryo injections. DNA oligos encoding short hairpin RNAs (shRNA) targeting Xenopus $\mathrm{Na}_{\mathrm{V}} 1.2$ (AY121368), dsRed (AY679106), or salt-inducible kinase (SIK; 1319975) were cloned downstream of a U6 RNA Pol III promoter; the vector also contained cytomegalovirus-driven green fluorescent protein (GFP) (Miskevich et al., 2006). RNA interference (RNAi) target sequences are as follows: $\mathrm{Na}_{\mathrm{V}} 1.2,5^{\prime}$-GCCATGGAGCATTATCCAATG-3'; dsRed, 5' -GTTCAAGTCCATCTACATGGC-3'; and SIK, 5'-GCCAGTTCTCTACTCACAAAC- $3^{\prime}$. These constructs were microinjected into one- or two-cell stage embryos. The presence of the shRNA in st. 40 tail tissues was identified by GFP fluorescence, indicating that the plasmid was expressed in the cells. For overexpression, full-length $\beta$-galactosidase or human $\mathrm{Na}_{\mathrm{V}} 1.5$ (GI:184038) RNA were transcribed using mMessage Machine kit (Ambion). Approximately $5 \mathrm{ng}$ of each target was mixed with $500 \mathrm{pg}$ of GFP mRNA and was injected into two-cell embryos. Tails with good GFP expression were selected before amputation for experiments.

Modulation of sodium flux and imaging of reporter dyes. At $23 \mathrm{hpa}$, st. 40 tadpoles were incubated in $90 \mu \mathrm{M}$ CoroNa Green indicator dye (Invitrogen) in $0.1 \times$ MMR for $45 \mathrm{~min}$ and washed twice in $0.1 \times$ MMR and 30 $\mu \mathrm{M} N$-benzyl-p-toluene sulfonamide (BTS; Tocris Bioscience) to immobilize tadpole movement. At $24 \mathrm{hpa}$, the CoroNa Green signal was excited at $488 \mathrm{~nm}$ and fluorescence emission data were collected at $516 \mathrm{~nm}$. Data were analyzed using IPLab software (BD Biosciences). For induction of $\mathrm{Na}^{+}$current, $0.1 \times$ MMR was supplemented with sodium gluconate (Sigma) to increase the $\mathrm{Na}^{+}$concentration to $90 \mathrm{~mm}$. For refractory period analysis, tails were amputated at st. $46-47$, and at $18 \mathrm{hpa}$ animals were treated with or without $90 \mathrm{~mm}$ sodium and $20 \mu \mathrm{M}$ monensin (Sigma) in $0.1 \times$ MMR with $90 \mu \mathrm{M}$ CoroNa Green for $45 \mathrm{~min}$ and washed twice in $0.1 \times \mathrm{MMR}$ and $50 \mu \mathrm{M}$ BTS. Imaging of transmembrane potential using DiBAC4(3) (Invitrogen) with controls was performed exactly as described previously (Adams et al., 2007).

In situ hybridization and immunohistochemistry. In situ hybridization was performed according to standard protocols (Harland, 1991) with probes to $\mathrm{Na}_{\mathrm{V}} 1.2$ (AY121368), $\mathrm{Na}_{\mathrm{V}} 1.5$ (Armisén et al., 2002), Notch1 (Coffman et al., 1990), Msxl (Feledy et al., 1999), and SIK (1319975). Xenopus embryos were fixed overnight in MEMFA buffer (Sive et al., 2000 ), heated for $2 \mathrm{~h}$ at $65^{\circ} \mathrm{C}$ in $50 \%$ formamide (to inactivate endogenous alkaline phosphatases), permeabilized in PBS and $0.1 \%$ Triton X-100 for $30 \mathrm{~min}$, and processed for immunohistochemistry using alkaline phosphatase secondary antibody (Levin, 2004) until signal was op- timal and background minimal. The expression profiles represent consensus patterns obtained from the analysis of 8-12 tails at each stage. Anti- $\mathrm{Na}_{\mathrm{V}} 1.2$ (Millipore), anti-acetylated $\alpha$-tubulin (Sigma), and antiphospho-H3 (Millipore) antibodies were used at 1:1000. Quantification of phospho-H3-positive cells were performed as described previously (Adams et al., 2007).

Cloning and gene expression. A tBLASTn search using mammalian SIK sequences identified a homologous Xenopus laevis cDNA clone \#6641975 (accession \#BU915306) in the Xenopus Gene Collection library. This clone was purchased and the sequence of this clone was submitted to GenBank (accession \#1319975). Fifteen to twenty regeneration buds (st. 40; $24 \mathrm{hpa}$ ) were collected and RNA isolated by Trizol (Invitrogen). A cDNA library was generated using the SMART cDNA synthesis kit (Clontech). Primers designed to the sequence $5^{\prime}$-TCCAGTCAGTTTCCGAGAAGGCAGACG-3' (forward); 5'-GCACCAGGTTCTGCATCTGCTGGGAATG'-3' (reverse) were used to identify the presence of the Xenopus homolog in the cDNA library. To detect gene expression by reverse transcription PCR, 15-20 regeneration buds from amputated tail were collected and RNA isolated by Trizol (Invitrogen). RNA was reverse transcribed using the Quantitect RT kit (Qiagen) to generate cDNA for real-time PCR analysis. Primers used were NaV1.2 (forward, 5'-GCAGCCACTGCTACCCCCAC-3'; reverse, 5'-GCACTGCCACCATTCCCGGT-3') and EF1 (forward, 5'-CAGGCCAGATTGGTGCTGGATATGC-3'; reverse, $5^{\prime}$-GCTCTCCACGCACATTGGCTTTCCT-3'). Target expression was normalized to EF1 expression.

Statistical analysis. To compare tail regeneration experiments, raw data from scoring was used. Comparison of two treatments was analyzed with Mann-Whitney $U$ test for ordinal data with tied ranks, using normal approximation for large sample sizes. Multiple treatments were compared using a Kruskal-Wallis test, with Dunn's Q corrected for tied ranks. All other experiments were analyzed using a Student's $t$ test.

\section{Results}

\section{Requirement for sodium transport in regeneration}

We identified a requirement for sodium transport in the course of a chemical genetics screen for bioelectric regulators specifically controlling regeneration (Adams et al., 2007). MS222 (tricaine) is a well known inhibitor of all voltage-gated sodium channels (VGSCs or $\mathrm{Na}_{\mathrm{V}} \mathrm{s}$ ) (Hedrick and Winmill, 2003) that blocks inward sodium currents (Frazier and Narahashi, 1975). Treatment of animals with either 150 or $250 \mu \mathrm{M}$ MS222 immediately after tail amputation for the duration of the $7 \mathrm{~d}$ assay significantly inhibited regenerative ability, as calculated using the composite RI (supplemental Fig. S1, available at www.jneurosci.org as supplemental material) $(\mathrm{RI}=114, n=65$; and $\mathrm{RI}=44, n=63$, respectively) in a dose-dependent manner when compared with control siblings $(\mathrm{RI}=265, n=68, p<0.01)$ (Fig. $1 A, B)$. MS222 treatment did not induce significant apoptosis in the bud and overall development of the animals (including growth of the primary tail) was normal, suggesting that this is a regeneration-specific effect. Importantly, the concentrations used were approximately tenfold lower than those commonly used to induce tadpole paralysis ( $\mathrm{mM}$ range) and the phenotypes we describe occur in tadpoles with normal behavior and mobility. To demonstrate the effect of MS222-mediated $\mathrm{Na}_{\mathrm{V}}$ inhibition on sodium transport, we visualized sodium flux using CoroNa Green (Fig. 1C), a fluorescent sodium-indicator dye that selectively interacts with sodium ions and exhibits an increase in fluorescent emission upon binding (Meier et al., 2006). In intact tails, few cells appear positive for the CoroNa Green signal relative to the majority of the tail population. At $24 \mathrm{hpa}$, a strong CoroNa Green signal is seen in the regeneration bud region but not in the rest of the tail and trunk, suggesting a significant increase in sodium transport into the cells of the bud during regeneration. When the amputated tails were treated with MS222, the CoroNa Green signal was abolished $(n=$ 8 per treatment, $p<0.005$ ), confirming that inhibition of $\mathrm{Na}_{\mathrm{V}}$ 
abrogates sodium influx into the bud. Therefore, we conclude that modulation of $\mathrm{Na}_{\mathrm{V}}$-dependent sodium flux in bud cells is an important regulator of regeneration.

$\mathrm{Na}_{\mathrm{V}} \mathrm{s}$, the target of MS222 action, are plasma membrane proteins that regulate sodium influx into cells (Yu and Catterall, 2003). In Xenopus, $\mathrm{Na}_{\mathrm{V}} 1.2$ and $\mathrm{Na}_{\mathrm{V}} 1.5$ have been identified, and we examined their expression in the regeneration bud. $\mathrm{Na}_{\mathrm{V}} 1.5$ was not expressed (supplemental Fig. S2, available at www.jneurosci.org as supplemental material). Consistent with a role for $\mathrm{Na}_{\mathrm{V}} 1.2$ in the early processes of tail regeneration, $\mathrm{Na}_{\mathrm{V}} 1.2$ RNA was expressed by $18 \mathrm{hpa}$ in the mesenchymal cells of the regeneration bud and persisted as late as $2 \mathrm{~d}$ postamputation (Fig. 1D). $\mathrm{Na}_{\mathrm{V}} 1.2$ protein was similarly expressed (supplemental Fig. S2, available at www. jneurosci.org as supplemental material).

To confirm the molecular basis for the regeneration-relevant sodium signaling in tail regeneration, we next ablated $\mathrm{Na}_{\mathrm{V}} 1.2$ activity by RNAi using a plasmid encoding a short RNA hairpin construct specifically targeting the Xenopus $\mathrm{Na}_{\mathrm{V}} 1.2$ gene. The targeting vector carries a GFP marker (Miskevich et al., 2006) on the same plasmid, enabling the accurate selection of animals that expressed the RNAi construct in the distal tail. Real-time PCR quantification of $\mathrm{Na}_{\mathrm{V}} 1.2$ mRNA in the regeneration bud at $24 \mathrm{hpa}$ revealed an overall decrease of $40 \%$ when compared with controls, showing the effectiveness of $\mathrm{Na}_{\mathrm{V}} 1.2 \mathrm{RNAi}$ knockdown in vivo. Despite the necessarily mosaic uptake of $\mathrm{Na}_{\mathrm{V}} 1.2$ RNAi construct, expression of the $\mathrm{Na}_{\mathrm{V}} 1.2$ short RNAi hairpin in the tail region at the site of amputation was able to significantly inhibit tail regeneration $(\mathrm{RI}=198$, $n=100, p<0.01)$ compared with control RNAi targeting dsRed, a fluorescent protein that is not endogenous to Xenopus $(\mathrm{RI}=261, n=72)$, confirming our pharmacological loss-of-function data (Fig. $1 E)$. Although we cannot rule out additional contributions from as-yetunidentified $\mathrm{Na}_{\mathrm{V}}$ isoforms, these data demonstrate that $\mathrm{Na}_{\mathrm{V}} 1.2$ is specifically required for tail regeneration, reveal an important component of endogenous regenerative response in Xenopus, and identify a new role for voltage-gated sodium channels.

Early control of regenerative processes by sodium influx

To examine the temporal requirement for $\mathrm{Na}_{\mathrm{V}}$-mediated sodium transport during regeneration, we amputated tails of tadpoles, treated them with $250 \mu \mathrm{M}$ MS222 for specific durations, and assayed their regenerative ability. Exposure to $\mathrm{Na}_{\mathrm{V}}$ blocker MS222 for the first 24 hpa prevented tail regeneration in $45 \%$ of the tadpoles $(n=106)$, indicating that sodium transport plays a role in regeneration bud establishment. When the duration of MS222 treatment was expanded to include the first $48 \mathrm{hpa}, 78 \%$ of the tails failed to regenerate $(n=105)$, fully recapitulating the severity of phenotype seen when $\mathrm{Na}_{\mathrm{V}}$ inhibition occured throughout the entire $7 \mathrm{~d}$ required for regeneration $(n=103)$. We then examined the effect of $\mathrm{Na}_{\mathrm{V}}$ inhibition after amputation. MS222 treatment targeting $\mathrm{Na}_{\mathrm{V}}$ activity at 24 hpa resulted in $26 \%$ regenerative failure $(n=107)$, demonstrating that the initial expression of $\mathrm{Na}_{\mathrm{V}} 1.2$ at $18 \mathrm{hpa}$ is critical to initiating regeneration. However, addition of MS222 at $48 \mathrm{hpa}(n=63)$, after regenerative outgrowth has begun, had no effect. Together, these results are consistent with our data for $\mathrm{Na}_{\mathrm{V}} 1.2$ (Fig. 1D) and strongly suggest that sodium transport is principally required during the establishment and early outgrowth phases of regeneration. Given 
this early role, we next asked what is the relationship between sodium influx and the known later steps in tail regenerative outgrowth?

Rapidly rebuilding a tail requires the increase of proliferating cells observed at the regeneration bud by $48 \mathrm{hpa}$ (Adams et al., 2007). To understand the cellular basis for the regenerative failure caused by block of sodium transport, we examined proliferation in sodium flux-inhibited animals. During development, mitotic cells are observed to be randomly located in the growing tail (Adams et al., 2007). We quantified the number and distribution of proliferating cells in regenerating tails at 48 hpa using an antibody to phosphorylated histone $3 \mathrm{~B}(\mathrm{H} 3 \mathrm{P})$, a marker of the $\mathrm{G}_{2} / \mathrm{M}$ transition of the cell cycle that identifies mitotic cells in Xenopus and many other systems (Saka and Smith, 2001; Adams et al., 2006). $\mathrm{Na}_{\mathrm{V}}$ inhibition using MS222 treatment caused a $90 \%$ decrease in the number of mitotic cells in the regeneration bud region $(1.3 \pm 1.5, n=4)$ compared with control siblings (12.5 \pm $4.8, n=4, p<0.005)$. Many H3P-positive cells were seen in the wild-type regeneration bud but very few are detected in MS222treated buds (Fig. $2 \mathrm{~A}$, top). Importantly, no significant change in proliferation was seen in the central tail flank region $(71 \pm 27$ H3P-positive cells for controls compared with $66.3 \pm 10$ for MS222 treatment, $n=8, p=0.38)$, showing that $\mathrm{Na}_{\mathrm{V}}$-mediated sodium flux is not a general requirement for normal cell division. Together, these data demonstrate that sodium transport is necessary for the specific upregulation of proliferation in the regenerative growth region.

Another important requirement for regenerative growth is proper innervation (Singer, 1952, 1965). Thus, we examined the neuronal pattern in the amputated tail stumps of tadpoles treated with MS222 (Fig. $2 \mathrm{~A}$, bottom). In normal, 3-d-old tail regenerates, axons appear in bundles that grow and concentrate toward the end of the regenerate, in a direction parallel to the anterior-posterior axis. In contrast, MS222 treatment caused axons to extend circumferentially along the edge of the regeneration bud, perpendicular to the main axis of tail growth. Notably, the overall quantity of neurons appeared to be reduced compared with control siblings. These results suggest that sodium flux is required for proper innervation of the regenerate.

Several pathways have been shown to be required for driving regenerative outgrowth and patterning in the tail, including Notch, Msx1, and BMP (Beck et al., 2003, 2006; Sugiura et al., 2004). To determine whether these pathways are controlled by sodium influx, we performed in situ hybridization using genespecific RNA probes to examine the expression patterns of Notch and Msxl in the regeneration bud after $\mathrm{Na}_{\mathrm{V}}$ inhibition (Fig. $2 \mathrm{~B}$ ). At $48 \mathrm{hpa}$, Notch1 is normally expressed in the neural ampulla and in the mesenchymal region of the regeneration bud, and Msxl is expressed in the neural ampulla and at the epithelial edge of the regenerating tail tip. In contrast, MS222 treatment largely abolished expression of Notch1 and Msx1. Likewise, levels of BMP2, BMP4, and Delta were greatly reduced in the presence of MS222 (supplemental Fig. S2, available at www.jneurosci.org as supplemental material). Although not evidence for direct regulation, these results demonstrate that sodium flux acts upstream to induce the later expression of several key genes known to control downstream regenerative outgrowth and patterning.

\section{Induction of regeneration by a transient sodium current}

Mammals exhibit an age-dependent decrease in regenerative potential (Illingworth, 1974). Similarly, Xenopus tadpoles also show a loss of regenerative potential during the refractory period, an
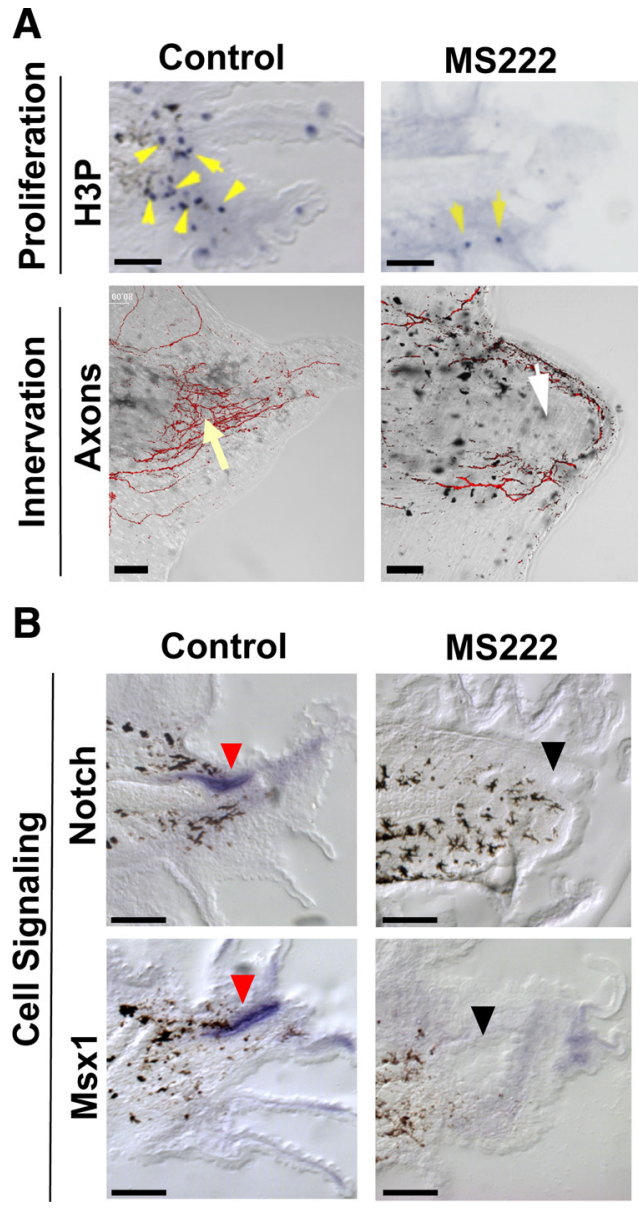

Figure 2. $\quad \mathrm{Na}_{\mathrm{V}}$-mediated sodium transport acts early during regeneration. $\boldsymbol{A}$, Effect of $\mathrm{Na}_{\mathrm{V}}$ inhibition (MS222) on proliferation and innervation. Top, Immunohistochemistry of $48 \mathrm{hpa}$ tails using an anti-H3P antibody (blue) in sagittal sections (yellow arrows indicate mitotic cells; melanocytes are black). Bottom, Tails (72 hpa) stained with acetylated $\alpha$-tubulin antibody to identify axons. Control axon bundles run parallel to the anterior-posterior axis and concentrate at the tip (yellow arrow). MS222 treatment reduces axons (white arrow) that trace along the edge. $\boldsymbol{B}$, Effect of $\mathrm{Na}_{V}$ inhibition on genes that regulate regenerative outgrowth (as shown by RNA in situ hybridization in sagittal sections at $48 \mathrm{hpa}$ ). Notch RNA (top) is expressed in the neural ampulla (red arrows) and in the regeneration bud mesenchyme, whereas Msx1 (bottom) is expressed solely in the neural ampulla. Gene expression is abolished after $\mathrm{Na}_{v} 1.2$ inhibition (black arrows). Scale bars, $250 \mu \mathrm{m}$.

endogenous period (st. 45-47) during development in which tadpoles are unable to regenerate tails (Beck et al., 2003). Our results are consistent with $\mathrm{Na}_{\mathrm{V}} 1.2$ expression being predictive of regenerative competency; it is absent in nonregenerating tail stumps, including those amputated during the refractory period (supplemental Fig. S2, available at www.jneurosci.org as supplemental material). Thus, induction of sodium current could be sufficient to promote regeneration during the nonregenerative refractory state.

Crucially, a primary role for sodium influx in the induction of reparative growth suggests that any functional $\mathrm{Na}_{\mathrm{V}}$ could fulfill this requirement. We therefore expressed the human cardiac sodium channel, $\mathrm{Na}_{\mathrm{V}} 1.5$ (Fraser et al., 2005), ubiquitously by early embryo injection and assessed its ability to rescue regeneration. As expected, ectopic expression of $\mathrm{hNa}_{\mathrm{V}} 1.5$ in refractory cut tails, where endogenous $\mathrm{Na}_{V} 1.2$ is absent (supplemental Fig. S2, available at www.jneurosci.org as supplemental material), did indeed rescue regeneration ( $\beta$-gal control, $\mathrm{RI}=10, n=82$; compared with $\left.\mathrm{hNa}_{\mathrm{V}} 1.5, \mathrm{RI}=39, n=116, p<0.001\right)$ (Fig. $\left.3 A, B\right)$. Support- 
ing this observation, expression of $\mathrm{hNa}_{\mathrm{V}} 1.5$ was also able to rescue regenerative failure (Adams et al., 2007) due to V-ATPase inhibition by concanamycin ( $\beta$-gal control, $\mathrm{RI}=120, n=145$; compared with $\mathrm{hNa}_{\mathrm{V}} 1.5$, $\mathrm{RI}=231, n=132, p<0.0001)$. These results confirm that sodium conductance, not a specific native $\mathrm{Na}_{\mathrm{V}}$ protein, is required for driving regenerative outgrowth.

We next asked whether directly modulating sodium transport without genetic manipulation promotes regeneration. Monensin is an ionophore that selectively transports sodium ions into cells (Mollenhauer et al., 1990). Tails of animals in the refractory period were amputated and, at $18 \mathrm{hpa}$ (recapitulating the timing of $\mathrm{Na}_{\mathrm{V}} 1.2$ expression), treated with $20 \mu \mathrm{M}$ monensin in a medium containing $90 \mathrm{~mm}$ sodium (normal culture medium contains $10 \mathrm{~mm}$ sodium). To confirm that monensin induces an increase in intracellular sodium levels, we used the CoroNa Green indicator dye to visualize sodium content in the amputated caudal stump. At 19 hpa, normal refractory tail buds showed very weak CoroNa Green signal (Fig. 3C1, white circle). In contrast, monensin-treated tails, after a $1 \mathrm{~h}$ current induction in high-sodium medium, showed a strong CoroNa Green fluorescence at the amputation site (Fig. 3C2, white circle), demonstrating that monensin treatment does increase intracellular sodium content in the regeneration bud.

We then assessed the consequence of monensin treatment on regeneration. During the refractory period, the regenerative ability of Xenopus tadpoles was extremely poor $(\mathrm{RI}=16.8, n=179)$. Most animals failed to regenerate any tissue in the amputated tails (Fig. 3C3). Strikingly, treatment at $18 \mathrm{hpa}$ with $20 \mu \mathrm{M}$ monensin in a medium containing $90 \mathrm{~mm}$ sodium for just $1 \mathrm{~h}$ induced a significant increase in both the quality and quantity of regeneration $(\mathrm{RI}=48.5, n=101, p<0.001)$ compared with refractory controls (Fig. $3 C 4, D)$. The animals were developmentally normal and did not grow ectopic tissues. Importantly, the same treatment with either monensin alone $(\mathrm{RI}=10.8$, $n=117)$ or high extracellular sodium alone $(\mathrm{RI}=20.8, n=125)$ did not improve regenerative ability $(p>0.05)$, showing that neither monensin nor high extracellular sodium alone is capable of this effect and ruling out effects of osmolarity changes as an important factor in this treatment. It is the induced sodium influx that promotes regeneration. Consistent with our hypothesis, the same monensin induction method was observed to rescue another nonregenerative condition, caused by a pharmacological block of apoptosis (supplemental Fig. S3, available at www. jneurosci.org as supplemental material). Thus, the sufficiency of a transient pulse of sodium current at 18 hpa to restore regen-

C

D

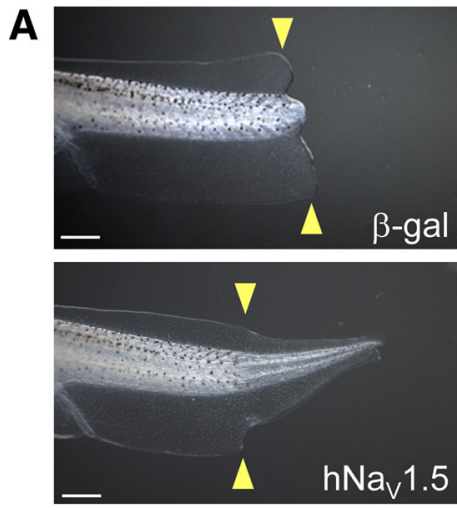

B
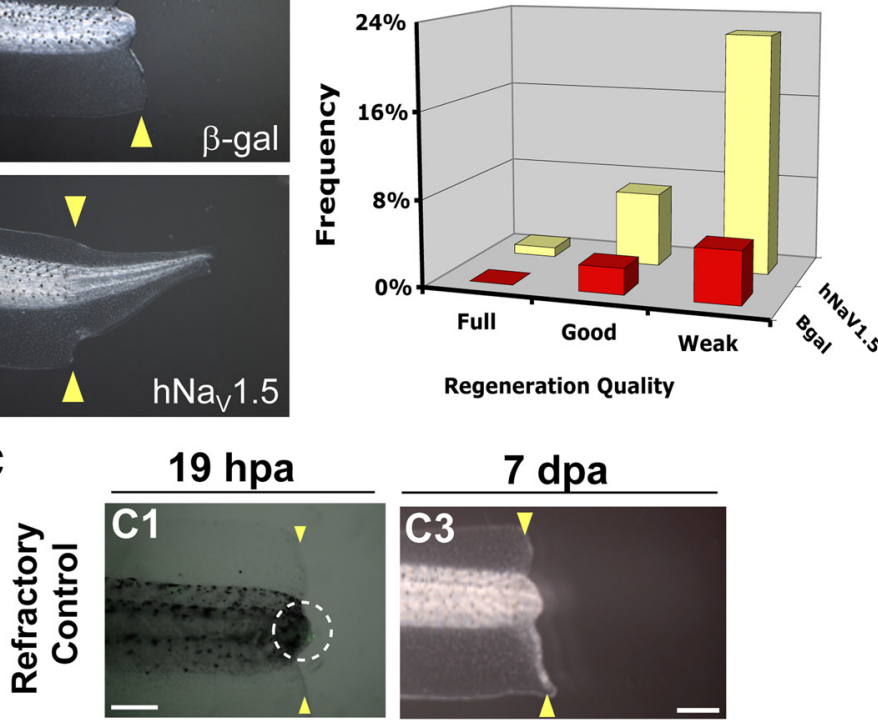

Regeneration Quality
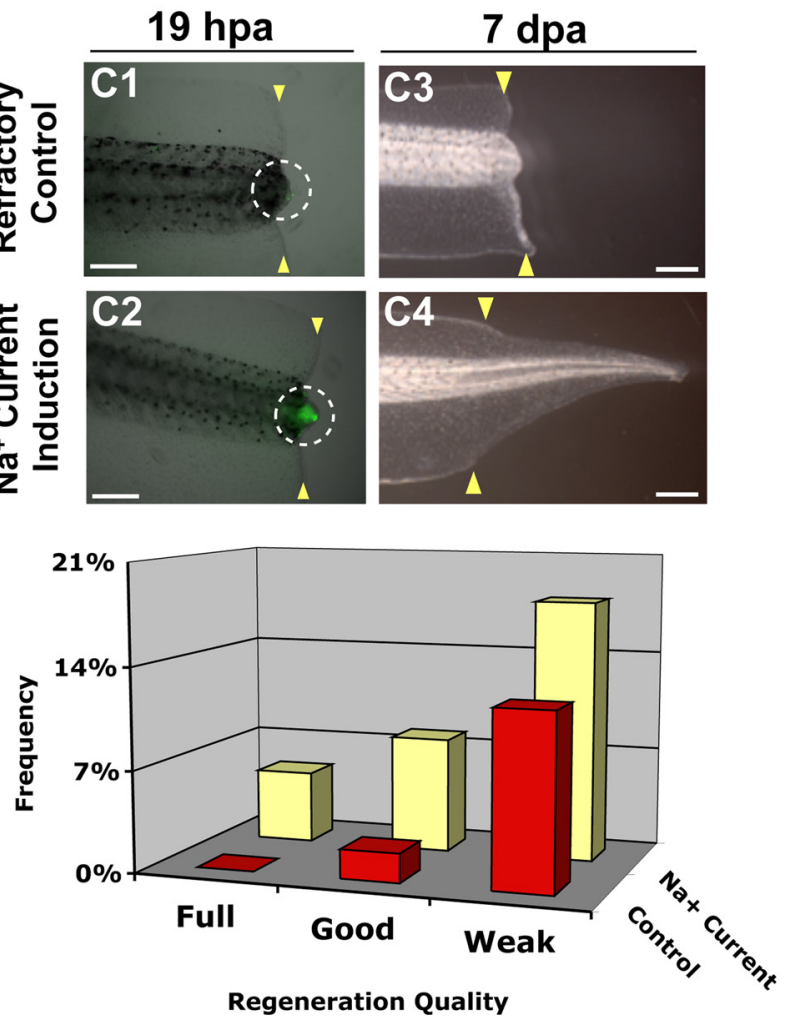

Figure 3. Transient induction of sodium current drives regeneration. $\boldsymbol{A}$, Regeneration rescue by human $\mathrm{Na}_{\mathrm{V}} 1.5\left(\mathrm{~h} \mathrm{Na}_{\mathrm{v}} 1.5\right)$. Control tail stumps ( $\beta$-gal-injected) cut during the refractory period regenerate poorly, which is rescued by hNa 1.5 expression. $\boldsymbol{B}$, Effects of regeneration rescue by $\mathrm{hNa}_{\mathrm{v}} 1.5$ during refractory period block. C, CoroNa Green analysis of sodium-current induction. C1 Control (vehicle only), noninduced refractory stage bud has little CoroNa Green signal. C2, Induction with $90 \mathrm{~mm}$ sodium and $20 \mu \mathrm{m}$ monensin for $1 \mathrm{~h}(18-19 \mathrm{hpa}$ ) significantly increases intracellular sodium (green). Images are merged brightfield and fluorescence f the same exposure time. White circle, Refractory bud. (3, Most refractory stage amputations fail to regenerate. (4, Stimulation with sodium current restores full regeneration. D, Transient sodium current rescues nonregenerative wound epidermis. Stimulation of sodium current increased regeneration more than twofold and improved regeneration quality compared with control siblings (treated with vehicle only, $0.01 \%$ ethanol). Treatment with either monensin or $90 \mathrm{~mm}$ sodium alone showed no effect. Scale bars: $A, 1 \mathrm{~mm} ; \boldsymbol{C}, 500 \mu \mathrm{m}$.

eration demonstrates that control of the intracellular sodium level in the regeneration bud can be used as a brief treatment to initiate regeneration of a vertebrate neuromuscular appendage. This observation suggests that, surprisingly, this instructive signal does not have to be present at the time of injury and is not required long-term to drive regeneration.

Regenerative control through modulation of intracellular sodium levels

To gain a detailed mechanistic understanding of $\mathrm{Na}_{\mathrm{V}}$ activity, we examined the consequences of modulating sodium ion transport 

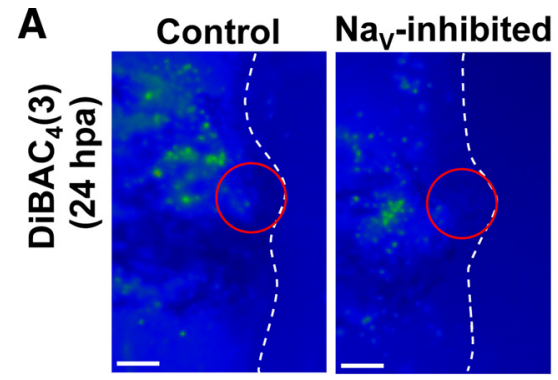

\section{5}

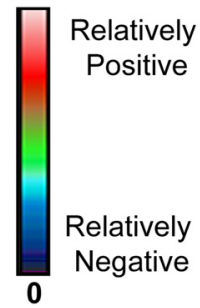

B

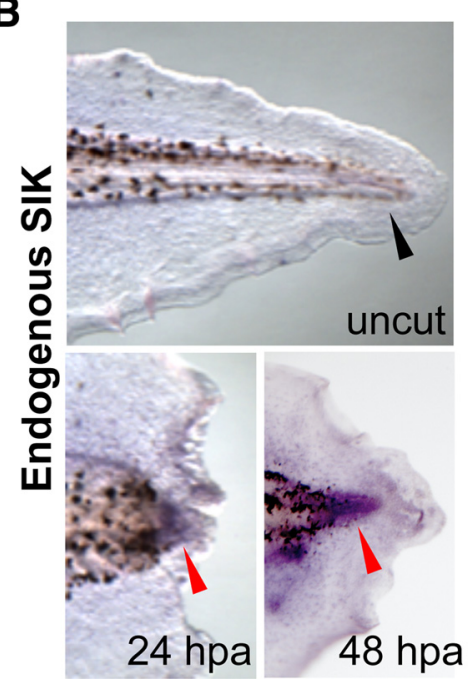

C
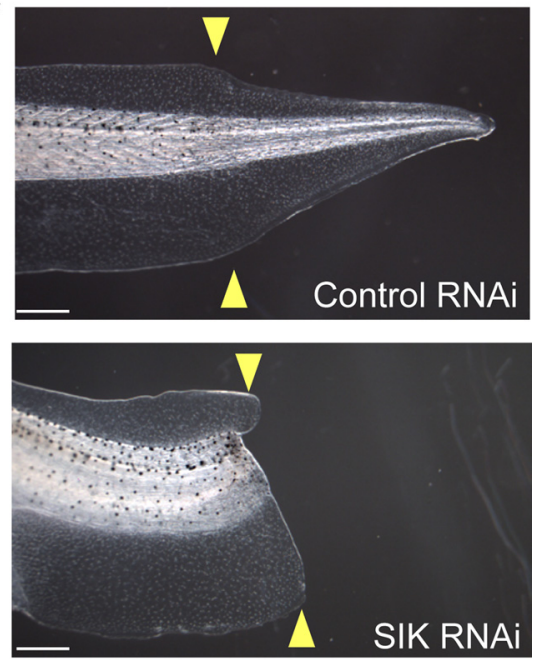

Figure 4. Salt-inducible kinase is required for tail regeneration. $A$, Comparison of the relative voltage patterns of tail regeneration buds at $24 \mathrm{hpa}$ using the voltage dye, $\operatorname{DiBAC}_{4}(3)$. Green is more depolarized than blue. Distal tail end (amputation site) is outlined in white. Scale bar, $100 \mu \mathrm{m}$. The regeneration bud (red circle) of controls was polarized (blue color). MS-222-treated buds show a similar pattern. $\boldsymbol{B}$, RNA in situ hybridization for endogenous SIK in whole-mount cut tails. SIK is expressed in the regeneration bud at 24 and $48 \mathrm{hpa}$ (red arrows) but not in uncut tails (black arrow). C, Effect of SIK RNAi on regeneration. SIK RNAiexpressing tadpoles fail to regenerate but develop normally.

in the regenerating tail. $\mathrm{Na}_{\mathrm{V}}$ activity is also a well known major determinant of some cells' membrane potential $\left(V_{\mathrm{mem}}\right)$, thus sodium flux could regulate regeneration by modulating the membrane voltage state of the regeneration bud. Using DiBAC4(3), we did not observe any changes in membrane voltage in the regeneration bud cells of MS-222-treated tails compared with controls (Fig. $4 A$, red circle), suggesting that, rather than changes in transmembrane potential, it is the sodium ion concentration per se that is the mechanism by which $\mathrm{Na}_{\mathrm{V}}$ function controls regenerative behavior.

One known effector of sodium ion-based signaling is the saltinducible kinase (SIK), a member of the AMP-activated protein kinase family that responds to changes in intracellular sodium levels (Sanz, 2003). Because SIK is a potential candidate to act as a molecular sensor of $\mathrm{Na}_{\mathrm{V}}$ activity during regeneration, we searched for and were able to identify a single Xenopus SIK clone from a regeneration bud-specific cDNA library, which a BLAST search showed is most homologous to the SIK2 isoform. X-SIK is expressed in the regeneration bud at 24 and 48 hpa but not in the uncut tail (Fig. $4 B$ ). We found that when a SIK RNAi construct was expressed in the tail, overall development was normal but regeneration was significantly reduced compared with control dsRed RNAi (control, RI = 234; SIK, RI $=151 ; n=207, p<$ 0.001) (Fig. 4C), demonstrating that SIK is indeed required for this process. Furthermore, pharmacological inhibition of SIK using staurosporine (STS) after sodium current induction during the refractory period also successfully blocked regeneration (no
STS, RI $=54.4 ; 10 \mathrm{~nm} \mathrm{STS,} \mathrm{RI}=1.8 ; n=$ 225, $p<0.001)$. Together, these results suggest that, as occurs in rats (Stenström et al., 2009), Xenopus SIK may transduce physiological sodium transport activity into second messenger cascades that control important cell functions necessary for tail regeneration, highlighting an important role for SIK during regeneration.

\section{Discussion}

Voltage-gated sodium channels have mainly been studied for their role in mediating the conduction of rapid electrical signaling in excitable cells of the nervous system and muscle (Diss et al., 2005), although roles in directing cell migration are beginning to be dissected (Brackenbury et al., 2008). The importance of bioelectric cues in regenerative events has been suggested for a very long time (Mathews, 1903; Lund, 1947). Both classical and recent work has indicated a requirement for sodium and electric fields in natural vertebrate appendage regeneration (Borgens et al., 1979; Robinson, 1983; Reid et al., 2009). However, the molecular source of regeneration-relevant currents in nonexcitable cells and the cell-biological consequences of their modulation remain largely unknown. Here we reveal a novel and unexpected role for $\mathrm{Na}_{\mathrm{V}^{-}}$ mediated sodium transport regulation of regeneration in a complex vertebrate structure. We show that sodium transport is required during the initiating stage of tail regeneration in Xenopus. $\mathrm{Na}_{\mathrm{V}} 1.2$, but not $\mathrm{Na}_{\mathrm{V}} 1.5$, is specifically expressed during endogenous regeneration and its expression is a predictor of regenerative abilityalthough additional unidentified $\mathrm{Na}_{\mathrm{V}} s$ may also play a role in this process. It should be kept in mind that, although our quantitative analyses clearly indicate the efficacy of loss- and gain-of-function approaches targeting $\mathrm{Na}_{\mathrm{V}} 1.2$, the penetrance of the inhibition and rescue had to be artificially suppressed by titering the treatments to low levels. This was made necessary by the importance of $\mathrm{Na}_{\mathrm{V}} 1.2$ channels in the nervous system and heart; thus, overly strong modulation of sodium currents results in toxicity that would have made regeneration phenotypes impossible to detect. Along these lines, for example, our experiments with the $\mathrm{Na}_{\mathrm{V}} 1.2$ blocker MS-222 were conducted at low levels that did not impair nerve function (i.e., did not cause paralysis or change in behavior).

Our results reveal both the upstream molecular pathways responsible for $\mathrm{Na}_{\mathrm{V}} 1.2$-dependent induction of sodium flow (V-ATPase activity) (supplemental Fig. S2, available at www. jneurosci.org as supplemental material) and those downstream events controlled by sodium influx (Notch and Msx1 induction). The data characterized the effects of functional inhibition of sodium transport at several levels: physiologically (decrease of sodium influx), molecularly (lack of induction of regeneration-specific late genes, an effect likely mediated by SIK), and cellularly (changes in cell proliferation and axonal patterning). Together, these data suggest a model (Fig. 5) that integrates the biochemical, genetic, and 


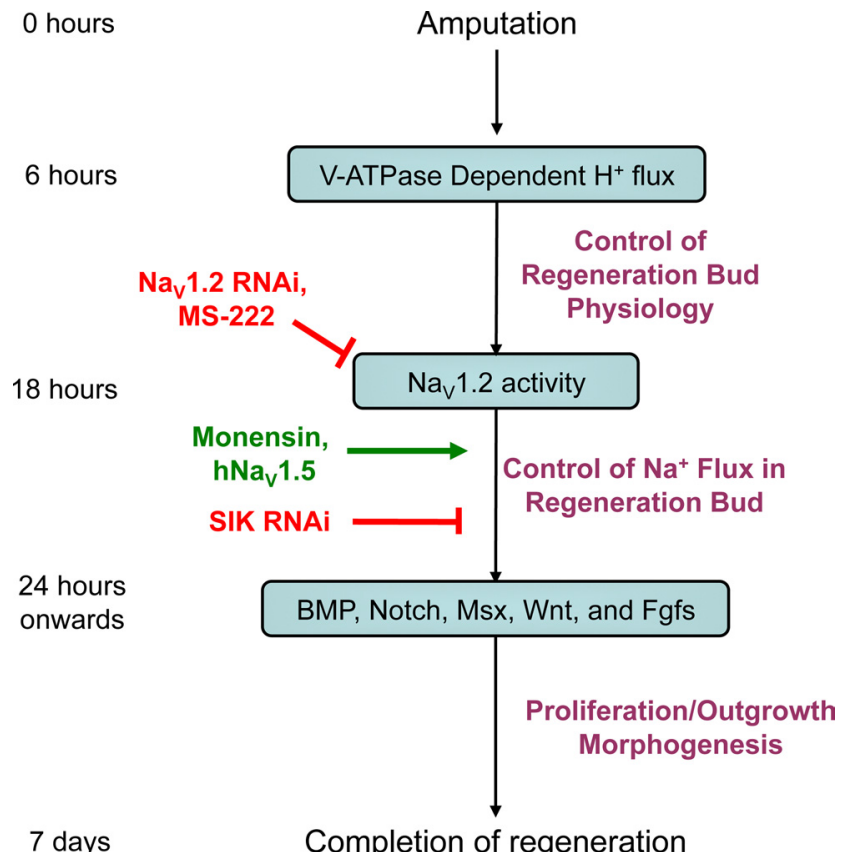

Figure 5. A model integrating $\mathrm{Na}_{\mathrm{V}}$ in regeneration. By $6 \mathrm{hpa}$, the $\mathrm{H}^{+}$pump V-ATPase is expressed in the regeneration bud where it regulates the membrane voltage of the bud. V-ATPase activation results in the upregulation of $\mathrm{Na}_{\mathrm{V}} 1.2$ by $18 \mathrm{hpa}$. Ablation of $\mathrm{Na}_{\mathrm{V}} 1.2$ expression (RNAi) or $\mathrm{Na}_{\mathrm{V}}$ function (pharmacological treatment) inhibits regeneration. $\mathrm{Na}_{\mathrm{V}}$ activity enables sodium ions to enter regeneration bud cells and, potentially through SIK, to activate downstream pathways (such as BMP and Notch) by $24 \mathrm{hpa}$, driving regenerative outgrowth and patterning. By $7 \mathrm{~d}$ after injury, the rebuilding of the tail is largely complete. Importantly, monensin-mediated induction of a transient sodium flux into nonregenerative buds is sufficient to restore full tail regeneration, demonstrating that intracellular sodium signaling is a key regulator of regeneration able to initiate repair even after a nonregenerative wound epithelium has formed.

physiological data into a stepwise pathway leading to regeneration of the tail. Importantly, our model shows that the bioelectric signals produced by $\mathrm{V}$-ATPase and $\mathrm{Na}_{\mathrm{V}}$ form a physiological module; this module is both induced by and, in turn, influences gene expression while participating in the orchestration of multiple aspects of epimorphic regeneration.

A mechanism by which $\mathrm{Na}_{\mathrm{V}}$ might be expected to function is through the control of membrane voltage. We found no evidence of this (Fig. 4), suggesting that regeneration bud cells regulate other transport events to maintain voltage despite changing levels of sodium ions. Furthermore, the results of the monensin experiments show that direct sodium increases are functionally instructive for regeneration during nonregenerative states that occur naturally (refractory period) (Fig. 3) or are induced chemically (apoptosis inhibition) (supplemental Fig. S3, available at www.jneurosci.org as supplemental material). These currents are endogenously provided by $\mathrm{Na}_{\mathrm{V}}$ (and in Xenopus by $\mathrm{Na}_{\mathrm{V}} 1.2$ ) but can be strikingly recapitulated by a very rapid, transient external induction of sodium flux. Although extracellular sodium currents are known to be a major component of transepithelial potentials (TEP) during repair in both Xenopus (Rajnicek et al., 1988; Jenkins et al., 1996) and humans (Shapiro et al., 2005), the mechanism we identified is different because it does not rely on modulation of the TEP. Our data most clearly support a role for intracellular sodium ions intrinsically guiding regenerative outgrowth through cell proliferation and gene expression in the bud-a novel mechanism for regeneration.

How then, does sodium flow control downstream events? Unlike calcium, relatively few effectors of sodium influx have been identified. Chemical treatments using inhibitors of either the sodium-activated potassium channel, Slo2.2 (Slo Inibitor treatment, $\mathrm{RI}=270, n=74$; compared with control, $\mathrm{RI}=258, n=$ $33 ; p>0.05$ ) or sodium/calcium exchangers (Adams et al., 2007) did not affect tail regeneration, suggesting that the effect of sodium is unlikely to be mediated by secondary effects on calcium. A likely candidate for transducing changes of intracellular sodium level into second messenger cascades is SIK, which has been implicated in stress response (Wang et al., 2008), global regulation of gene expression (Verdin et al., 2003), and may potentially regulate regenerative pathway genes such as BMPs (Shakèd et al., 2008). The identification of an increase of intracellular sodium as a key regulator of regenerative response is a crucial new area for future work integrating the roles of bioelectric signaling and the more canonical biochemical pathways (Blackiston et al., 2009; McCaig et al., 2009).

$\mathrm{Na}_{\mathrm{V}}$ regulates regenerative growth in part by its influence on downstream signaling genes, including Notch1, BMP, and Msx1. These genes are also important for regeneration in other systems such as the tadpole limb, zebrafish fin and heart, and mammalian digit tips (Poss et al., 2000; Han et al., 2003). Consistent with the conserved roles of ion currents in regulating global patterning and morphogenetic cues from fungi to mammals (Nuccitelli et al., 1986; Levin, 2009), it is likely that the early mechanisms of ion transporter signaling in regeneration are used in other species and structures, in addition to the tail.

We show that several nonregenerative states (e.g., agedependent decline or refractory period, and an apoptosisinhibited failure of regeneration) can be rescued by a $1 \mathrm{~h}$ pharmacological treatment that recapitulates the $\mathrm{Na}_{\mathrm{V}}$-dependent influx of sodium in caudal bud cells and restores regeneration. Remarkably, this treatment only induced tail structures and did not generate ectopic growths or neoplasia during development, suggesting that sodium flow could act as a master control point to initiate tightly coordinated, self-limiting, downstream morphogenetic cascades (supplemental Fig. S4, available at www. jneurosci.org as supplemental material). This result has several important implications for regenerative medicine. The ability to restore regeneration using a temporally controllable pharmacological approach not requiring gene therapy is extremely exciting. Moreover, that a short-term induction of sodium current was sufficient to restore regeneration suggests the possibility that the correct initiating signal is not required long-term to drive completion of the process - a highly desirable property for regenerative therapies.

Most importantly, our finding that the amputated refractory tail can be induced to regenerate as late as $18 \mathrm{~h}$ after amputation reveals that tissues normally fated for regenerative failure still maintain their intrinsic ability and can be reprogrammed to reactivate regeneration. Furthermore, this observation challenges the view that differences in wound healing decisively determine regenerative ability (Tassava and Olsen, 1982; Campbell and Crews, 2008). In Xenopus tail regeneration, regenerative wound healing is completed by $8 \mathrm{hpa}$ (Ho and Whitman, 2008). In contrast, refractory tail amputation results in a thickened, nonregenerative wound epidermis (Beck et al., 2003), which can be observed by 18 hpa (supplemental Fig. S5, available at www. jneurosci.org as supplemental material). Thus, the induction of a regenerative signal at $18 \mathrm{hpa}$ is not predicted to impact wound healing. Our results demonstrate that nonregenerative wound healing is not a permanent block to the later induction of regeneration. That the instructive capacity of the wound epithelium can be overcome by biophysical signals such as that mediated by 
$\mathrm{Na}_{\mathrm{V}}$ reveals the existence of a competency window within which cells retain their capability to initiate the regenerative program-if the appropriate signals are provided. It also suggests that potential therapeutic treatments need not be administered immediately after acute injury (or indeed before injury, as is done in many studies of regenerative induction in this system). Further studies of the $\mathrm{Na}_{\mathrm{V}}$-mediated sodium transport regenerative signaling pathway will provide a detailed understanding of the requirements for initiating regeneration during different nonregenerative conditions and a more complete understanding of the molecular physiology of regeneration. Capitalizing upon such bioelectrical cues will be a rewarding and exciting area for regenerative medicine and developmental biology.

\section{References}

Adams DS, Masi A, Levin M (2006) Xenopus tadpole tail regeneration requires the activity of the proton pump V-ATPase, and proton pumping is sufficient to partially rescue the loss of function phenotype. Dev Biol 295:355-356.

Adams DS, Masi A, Levin M (2007) H+ pump-dependent changes in membrane voltage are an early mechanism necessary and sufficient to induce Xenopus tail regeneration. Development 134:1323-1335.

Armisén R, Fuentes R, Olguín P, Cabrejos ME, Kukuljan M (2002) Repressor element-1 silencing transcription/neuron-restrictive silencer factor is required for neural sodium channel expression during development of Xenopus. J Neurosci 22:8347-8351.

Beck CW, Christen B, Slack JM (2003) Molecular pathways needed for regeneration of spinal cord and muscle in a vertebrate. Dev Cell 5:429-439.

Beck CW, Christen B, Barker D, Slack JM (2006) Temporal requirement for bone morphogenetic proteins in regeneration of the tail and limb of Xenopus tadpoles. Mech Dev 123:674-688.

Beck CW, Izpisúa Belmonte JC, Christen B (2009) Beyond early development: Xenopus as an emerging model for the study of regenerative mechanisms. Dev Dyn 238:1226-1248.

Blackiston DJ, McLaughlin KA, Levin M (2009) Bioelectric controls of cell proliferation: ion channels, membrane voltage and the cell cycle. Cell Cycle 8:3519-3528.

Borgens RB, Vanable JW Jr, Jaffe LF (1979) Reduction of sodium dependent stump currents disturbs urodele limb regeneration. J Exp Zool 209:377-386

Brackenbury WJ, Djamgoz MB, Isom LL (2008) An emerging role for voltage-gated $\mathrm{Na}+$ channels in cellular migration: regulation of central nervous system development and potentiation of invasive cancers. Neuroscientist 14:571-583.

Campbell LJ, Crews CM (2008) Wound epidermis formation and function in urodele amphibian limb regeneration. Cell Mol Life Sci 65:73-79.

Chen Y, Lin G, Slack JM (2006) Control of muscle regeneration in the Xenopus tadpole tail by Pax7. Development 133:2303-2313.

Chera S, Ghila L, Dobretz K, Wenger Y, Bauer C, Buzgariu W, Martinou JC, Galliot B (2009) Apoptotic cells provide an unexpected source of Wnt3 signaling to drive hydra head regeneration. Dev Cell 17:279-289.

Coffman C, Harris W, Kintner C (1990) Xotch, the Xenopus homolog of Drosophila notch. Science 249:1438-1441.

Diss JK, Stewart D, Pani F, Foster CS, Walker MM, Patel A, Djamgoz MB (2005) A potential novel marker for human prostate cancer: voltagegated sodium channel expression in vivo. Prostate Cancer Prostatic Dis $8: 266-273$.

Feledy JA, Beanan MJ, Sandoval JJ, Goodrich JS, Lim JH, Matsuo-Takasaki M, Sato SM, Sargent TD (1999) Inhibitory patterning of the anterior neural plate in Xenopus by homeodomain factors Dlx3 and Msx1. Dev Biol 212:455-464.

Fraser SP, Diss JK, Chioni AM, Mycielska ME, Pan H, Yamaci RF, Pani F, Siwy Z, Krasowska M, Grzywna Z, Brackenbury WJ, Theodorou D, Koyutürk M, Kaya H, Battaloglu E, De Bella MT, Slade MJ, Tolhurst R, Palmieri C, Jiang J, et al. (2005) Voltage-gated sodium channel expression and potentiation of human breast cancer metastasis. Clin Cancer Res 11:5381-5389.

Frazier DT, Narahashi T (1975) Tricaine (MS-222): effects on ionic conductances of squid axon membranes. Eur J Pharmacol 33:313-317.

Gargioli C, Slack JM (2004) Cell lineage tracing during Xenopus tail regeneration. Development 131:2669-2679.
Han M, Yang X, Farrington JE, Muneoka K (2003) Digit regeneration is regulated by Msx1 and BMP4 in fetal mice. Development 130:5123-5132.

Harland RM (1991) In situ hybridization: an improved whole mount method for Xenopus embryos. In: Xenopus laevis: practical uses in cell and molecular biology (Kay BK, Peng HB, eds), pp 685-695. San Diego: Academic.

Hedrick MS, Winmill RE (2003) Excitatory and inhibitory effects of tricaine (MS-222) on fictive breathing in isolated bullfrog brain stem. Am J Physiol Regul Integr Comp Physiol 284:R405-R412.

Ho DM, Whitman M (2008) TGF-beta signaling is required for multiple processes during Xenopus tail regeneration. Dev Biol 315:203-216.

Illingworth CM (1974) Trapped fingers and amputated finger tips in children. J Pediatr Surg 9:853-858.

Jenkins LS, Duerstock BS, Borgens RB (1996) Reduction of the current of injury leaving the amputation inhibits limb regeneration in the red spotted newt. Dev Biol 178:251-262.

Levin M (2004) A novel immunohistochemical method for evaluation of antibody specificity and detection of labile targets in biological tissue. J Biochem Biophys Methods 58:85-96.

Levin M (2009) Errors of geometry: regeneration in a broader perspective. Semin Cell Dev Biol 20:643-645.

Li F, Huang Q, Chen J, Peng Y, Roop DR, Bedford JS, Li CY (2010) Apoptotic cells activate the "phoenix rising" pathway to promote wound healing and tissue regeneration. Sci Signal 3:ra13.

Lund E (1947) Bioelectric fields and growth. Austin: University of Texas.

Mathews AP (1903) Electrical polarity in the hydroids. Am J Physiol 8:294-299.

McCaig CD, Song B, Rajnicek AM (2009) Electrical dimensions in cell science. J Cell Sci 122:4267-4276.

Meier SD, Kovalchuk Y, Rose CR (2006) Properties of the new fluorescent $\mathrm{Na}+$ indicator CoroNa Green: comparison with SBFI and confocal $\mathrm{Na}+$ imaging. J Neurosci Methods 155:251-259.

Miskevich F, Doench JG, Townsend MT, Sharp PA, Constantine-Paton M (2006) RNA interference of Xenopus NMDAR NR1 in vitro and in vivo. J Neurosci Methods 152:65-73.

Mochii M, Taniguchi Y, Shikata I (2007) Tail regeneration in the Xenopus tadpole. Dev Growth Differ 49:155-161.

Mollenhauer HH, Morré DJ, Rowe LD (1990) Alteration of intracellular traffic by monensin; mechanism, specificity and relationship to toxicity. Biochim Biophys Acta 1031:225-246.

Nieuwkoop PD, Faber J (1967) Normal table of Xenopus laevis (Daudin), 2nd Edition. Amsterdam: North-Holland Publishing Company.

Nuccitelli R, Robinson K, Jaffe L (1986) On electrical currents in development. Bioessays 5:292-294.

Poss KD, Shen J, Nechiporuk A, McMahon G, Thisse B, Thisse C, Keating MT (2000) Roles for Fgf signaling during zebrafish fin regeneration. Dev Biol 222:347-358.

Rajnicek AM, Stump RF, Robinson KR (1988) An endogenous sodium current may mediate wound healing in Xenopus neurulae. Dev Biol 128:290-299.

Reid B, Song B, McCaig CD, Zhao M (2005) Wound healing in rat cornea: the role of electric currents. FASEB J 19:379-386.

Reid B, Song B, Zhao M (2009) Electric currents in Xenopus tadpole tail regeneration. Dev Biol 335:198-207.

Robinson KR (1983) Endogenous electrical current leaves the limb and prelimb region of the Xenopus embryo. Dev Biol 97:203-211.

Saka Y, Smith JC (2001) Spatial and temporal patterns of cell division during early Xenopus embryogenesis. Dev Biol 229:307-318.

Sanz P (2003) Snf1 protein kinase: a key player in the response to cellular stress in yeast. Biochem Soc Trans 31:178-181.

Shakèd M, Weissmüller K, Svoboda H, Hortschansky P, Nishino N, Wölfl S, Tucker KL (2008) Histone deacetylases control neurogenesis in embryonic brain by inhibition of BMP2/4 signaling. PLoS One 3:e2668.

Shapiro S, Borgens R, Pascuzzi R, Roos K, Groff M, Purvines S, Rodgers RB, Hagy S, Nelson P (2005) Oscillating field stimulation for complete spinal cord injury in humans: a phase 1 trial. J Neurosurg Spine 2:3-10.

Singer M (1952) The influence of the nerve in regeneration of the amphibian extremity. Q Rev Biol 27:169-200.

Singer M (1965) A theory of the trophic nervous control of amphibian limb regeneration, including a re-evaluation of quantiative nerve requirements. In: Proceedings of regeneration in animals. 
Sive HL, Grainger RM, Harland RM (2000) Early development of Xenopus Laevis. New York: Cold Spring Harbor Laboratory.

Slack JM, Beck CW, Gargioli C, Christen B (2004) Cellular and molecular mechanisms of regeneration in Xenopus. Philos Trans R Soc Lond B Biol Sci 359:745-751.

Stenström K, Takemori H, Bianchi G, Katz AI, Bertorello AM (2009) Blocking the salt-inducible kinase 1 network prevents the increases in cell sodium transport caused by a hypertension-linked mutation in human alpha-adducin. J Hypertens 27:2452-2457.

Sugiura T, Taniguchi Y, Tazaki A, Ueno N, Watanabe K, Mochii M (2004) Differential gene expression between the embryonic tail bud and regenerating larval tail in Xenopus laevis. Dev Growth Differ 46: 97-105.

Tassava RA, Olsen CL (1982) Higher vertebrates do not regenerate digits and legs because the wound epidermis is not functional. Differentiation 22:151-155.
Tseng AS, Adams DS, Qiu D, Koustubhan P, Levin M (2007) Apoptosis is required during early stages of tail regeneration in Xenopus laevis. Dev Biol 301:62-69.

Verdin E, Dequiedt F, Kasler HG (2003) Class II histone deacetylases: versatile regulators. Trends Genet 19:286-293.

Wang B, Goode J, Best J, Meltzer J, Schilman PE, Chen J, Garza D, Thomas JB, Montminy M (2008) The insulin-regulated CREB coactivator TORC promotes stress resistance in Drosophila. Cell Metab 7:434-444.

Yu FH, Catterall WA (2003) Overview of the voltage-gated sodium channel family. Genome Biol 4:207.

Zhao M, Song B, Pu J, Wada T, Reid B, Tai G, Wang F, Guo A, Walczysko P, Gu Y, Sasaki T, Suzuki A, Forrester JV, Bourne HR, Devreotes PN, McCaig CD, Penninger JM (2006) Electrical signals control wound healing through phosphatidylinositol-3-OH kinase-gamma and PTEN. Nature 442:457-460.

Zupanc GK (2006) Neurogenesis and neuronal regeneration in the adult fish brain. J Comp Physiol A Neuroethol Sens Neural Behav Physiol 192:649-670. 